\title{
Osteoblastic differentiating potential of dental pulp stem cells in vitro cultured on a chemically modified microrough titanium surface
}

\author{
Marianna DE COLLI ${ }^{*}$, Milena RADUNOVIC ${ }^{2 *}$, Vincenzo L. ZIZZARI ${ }^{1}$, Viviana DI GIACOMO ${ }^{1}$, Chiara DI NISIO ${ }^{1}$, \\ Adriano PIATTELLI ${ }^{3}$, José L. CALVO GUIRADO ${ }^{4}$, Barbara ZAVAN ${ }^{5}$, Amelia CATALDI $^{1}$ and Susi ZARA ${ }^{1 *}$ \\ ${ }^{1}$ Department of Pharmacy, University "G. d'Annunzio" Chieti-Pescara, 66100 Chieti, Italy \\ ${ }^{2}$ School of Dental Medicine, University of Belgrade, Belgrade, Serbia \\ ${ }^{3}$ Department of Medical, Oral and Biotechnological Sciences, University G. d'Annunzio" Chieti-Pescara, 66100 Chieti, Italy \\ ${ }^{4}$ Faculty of Medicine and Dentistry, Universidad Catolica San Antonio De Murcia (UCAM), Murcia, Spain \\ ${ }^{5}$ Department of Biomedical Sciences, University of Padova, Padova, Italy \\ Corresponding author, Susi ZARA; E-mail: s.zara@unich.it
}

Titanium surface modification is critical for dental implant success. Our aim was to determine surfaces influence on dental pulp stem cells (DPSCs) viability and differentiation. Implants were divided into sandblasted/acid-etched (control) and sandblasted/acid-etched coated with calcium and magnesium ions ( $\mathrm{CaMg}$ ), supplied as composite (test). Proliferation was evaluated by MTT, differentiation checking osteoblastic gene expression, PGE2 secretion and matrix formation, inflammation by Interleukin 6 (IL-6) detection. MTT and IL-6 do not modify on test. A PGE2 increase on test is recorded. BMP2 is higher on test at early experimental points, Osterix and RUNX2 augment later. Alizarin-red $\mathrm{S}$ reveals higher matrix production on test. These results suggest that test surface is more osteoinductive, representing a start point for in vivo studies aiming at the construction of more biocompatible dental implants, whose integration and clinical performance are improved and some undesired effects, such as implant stability loss and further surgical procedures, are reduced.

Keywords: Differentiation markers, Dental pulp mesenchymal stem cells, PGE2, Titanium surfaces

\section{INTRODUCTION}

Endosseous titanium implants are widely used for restoration of completely and partially edentulous patients ${ }^{1,2)}$. The low density, high strength, durability and resistance to corrosion make titanium the material of choice for dental implants. One of the main purposes of research in the implant field was to improve the macroscopic and microscopic properties of the implant surface to achieve better treatment outcomes and long-term survival of osseointegrated implants s.5) $^{3-5}$. The implant surface/bone interface was considered a key determinant in the implant treatment success. Rougher implant surfaces, such as sandblasted and acid-etched, provide an appreciable biomechanical stability at the bone/implant area as well as a reduced release of inflammatory cytokines from the host tissues, in comparison to smooth machined surfaces ${ }^{6}$. To improve the osteoconductive and osteogenic properties for optimal osteointegration, the surface of titanium implants was constantly modified, mostly trying to increase its hydrophilicity ${ }^{7}$. The microstructure and the nanostructure of the titanium surface influenced the behavior of mesenchymal precursors of osteoblasts, thus affecting cell proliferation and differentiation towards the osteoblastic lineage ${ }^{8-11}$.

Mesenchymal stem cells are capable of self-renewal and, when appropriately induced, of differentiating into many cellular lineages ${ }^{12-14)}$, undifferentiated and highly clonogenic cells may be isolated from the dental pulp, the periodontal ligament and the dental papilla ${ }^{15,16)}$.

Dental pulp is an optimal source of dental pulp mesenchymal stem cells (DPSCs) because of the easy surgical samples withdrawal, the extremely low morbidity of the anatomical site after pulp harvesting, simple extraction of stem cells from harvested dental pulp, differentiation potential, and appreciable interaction with biomaterials ${ }^{17-19)}$.

DPSCs proliferate and are able to differentiate into mature odontoblasts/osteoblasts that produce mineralized matrix, thus are often used as in vitro models to simulate osteoblastic behavior, as elsewhere reported ${ }^{20)}$. The level of differentiation of the DPSCs greatly influences both the speed and the rate and the quality of matrix formation around the implant. This process is highly influenced by the nature of the implant surface.

Moreover, as the scientific literature widely demonstrated some inorganic ions, such as magnesium and calcium, are able to stimulate hard tissue regeneration by promoting osteoblasts proliferation and differentiation ${ }^{21,22)}$. It was hypothesized that the addition of calcium and magnesium inorganic ions $(\mathrm{CaMg})$ to the implant surface could increase the levels of PGE2 and the expression of BMP2 and RUNX2, generally considered osteoblastic differentiation markers.

As already stated above and elsewhere already reported $^{9)}$ the sandblasted and acid-etched implant surfaces improve the bone-implant interaction allowing a better osteointegration. For this reason our starting

*Authors who contributed equally to this work. 
point was represented by sandblasted and acid-etched titanium surfaces coated with $\mathrm{CaMg}$ to check if a chemically modified implant surface could affect DPSCs proliferation and differentiation into osteogenic cells lineage.

\section{MATERIALS AND METHODS}

\section{Sample preparation}

In this experiment 40 experimental commercially pure titanium discs (titanium grade 4) (Implacil De BortoliDental Product, São Paulo, Brazil) were used. Each disc was $5 \mathrm{~mm}$ in diameter and $2 \mathrm{~mm}$ thick.

Titanium surfaces were treated by sandblaster acid (SLA) - first they were blasted with 50-100 $\mu \mathrm{m} \mathrm{TiO}_{2}$ particles and then treated with maleic acid, as elsewhere reported in the scientific literature ${ }^{23)}$. The discs were then ultrasonically cleaned with an alkaline solution Riozyme IV-E Neutro Gold (Industria Farmaceutica Rioquimica Sao Jose do Rio Preto, Brazil) followed by a rinse with distilled water. These discs represented the Control Group, consisting of twenty discs, while 20 discs of the experimental group (Test Group) also had a layer of CaMg on its surface. The CaMg layer of the Test Group was obtained by blasting the samples with 30-80 $\mu \mathrm{m}$ CaMg microparticles, supplied as composite, at a pressure of $2.5 \mathrm{Mpa}$ with a distance of $5 \mathrm{~cm}$, in a decontaminated ambient (apparatus) with sterilized air. Each sample was prepared, packaged, and sterilized using the same requirements and care for implant packing $^{24)}$.

The discs were used for in vitro experiments, for which they were aseptically transferred to sterile 48well cell-culture trays and exposed to UV radiation for $1 \mathrm{~h}$.

\section{Isolation and cultivation of DPSCs}

The project obtained the approval of Local Ethical Committee of the University of Chieti (approval number 1173, date of approval 31/03/2016), in accordance with the Declaration of Helsinki. Dental pulp samples were obtained from third molars extracted in young adults (the age range was 18-28 years) which underwent orthodontic treatments. Informed consent was obtained from all the participants. Only impacted teeth without dental pathologies were included in the study. After the extraction, all the remaining soft tissues were mechanically removed and the external tooth surfaces were cleaned with a solution of clorhexidine $0.2 \%$. Within $5 \mathrm{~min}$ from extraction, the teeth were sliced to obtain dental pulp samples, by using a diamond cutter, making a $2-3 \mathrm{~mm}$ groove around the tooth and avoiding pulp exposure. Then, teeth were fractured off through the cutting line with a surgical lever, and pulp samples removed from the pulp chambers.

The dental pulp was washed with phosphatebuffered saline (PBS), kept in Minimum Essential Medium Eagle, alpha Modification ( $\alpha$-MEM, SigmaAldrich, St. Louis, MO, USA) with the addition of $10 \%$ of Foetal Bovine Serum (FBS) and 1\% of penicillin/ streptomicin (EuroClone, Milan, Italy) and delivered to the laboratory for stem cells isolation. Extracted pulp tissue was digested in a solution of $3 \mathrm{mg} /$ $\mathrm{mL}$ of collagenase type I (Sigma-Aldrich) in PBS, supplemented with $10 \%$ of FBS for $1 \mathrm{~h}$ at $37^{\circ} \mathrm{C}$. Afterwards, the digested tissue was resuspended in a solution of PBS with $2 \%$ FBS and was centrifuged at $1,000 \mathrm{rpm}$ for $10 \mathrm{~min}$. Pelleted cells were resuspended in standard growth medium ( $\alpha$-MEM supplemented with $10 \% \mathrm{FBS}$ and 1\% penicillin/streptavidin, GM) and seeded onto Petri dish. The medium was renewed every two/three days to remove cells debris. When cell culture reached sub-confluence (80-90\% of surface area), they were subcultured.

\section{Antigen expression in flow cytometry}

Cells were trypsinized, counted and $2 \times 10^{5}$ cells for each antigen were collected. After being washed in $1 \mathrm{~mL}$ of PBS, cells were resuspended in $50 \mu \mathrm{L}$ of PBS without calcium and magnesium and the appropriate amount of antibody was added: PE-CD29, FITC-CD45 and PECD105 (Ancell, Stillwater, MN, USA; $1 \mu \mathrm{L}$ ), PE-CD73 and FITC-CD90 (Becton Dickinson, Franklin Lakes, NJ, USA; $5 \mu \mathrm{L}$ ). After $30 \mathrm{~min}$ of incubation on ice, cells were washed and resuspended in $300 \mu \mathrm{L}$ of PBS prior to running on the flow cytometer. Only for the SSEA-4 antibody, cells were resuspended in $50 \mu \mathrm{L}$ of PBS without calcium and magnesium containing $5 \mu \mathrm{L}$ of a fixative reagent (PerFix-nc, no centrifuge assay Kit, Beckman Coulter, Brea, FL, USA), gently vortexed and incubated for $15 \mathrm{~min}$ at room temperature. Each sample was then resuspended in $200 \mu \mathrm{L}$ of a permeabilizing reagent (PerFix-nc, no centrifuge assay Kit, Beckman Coulter) containing $20 \mu \mathrm{L}$ of FITC-SSEA-4 antibody (Becton Dickinson), incubated for $30 \mathrm{~min}$ at room temperature and analyzed after the addition of 300 $\mu \mathrm{L}$ of final reagent $1 \mathrm{X}$ (PerFix-nc, no centrifuge assay Kit, Beckman Coulter). All the samples were run on a FC 500 flow cytometer (Beckman Coulter) with FL1 and FL2 detector in a log mode using the CXP analysis software (Beckmann Coulter). At least 15,000 events for each sample were acquired. The populations presented in the histogram were gated for the expression of each antigen. In all the experiments, SCs were always around the $50 \%$ of the entire population.

\section{DPSCs cultivation on titanium discs}

DPSCs from the fourth or fifth passage were seeded and cultivated on both control and test titanium discs at the density of 10,000 cells $/ \mathrm{cm}^{2}$ for 21 and 28 days. The cells were cultured using both GM and differentiation inducing medium ( $\alpha$-MEM, 10\% FBS, $10 \quad \mathrm{nM}$ dexamethasone, $0.2 \mathrm{mM}$ ascorbic acid, $10 \mathrm{mM}$ $\beta$-glycerophosphate, $1 \%$ penicillin/streptavidin, DM).

\section{Scanning electron microscopy (SEM) analysis}

For SEM analysis both control and test titanium discs without and with DPSCs, were fixed in $1 \%$ glutaraldehyde in $0.1 \mathrm{M}$ phosphate buffer for $30 \mathrm{~min}$ at $4^{\circ} \mathrm{C}$, washed in $0.1 \mathrm{M}$ phosphate buffer, dehydrated 
in ascending graded series of ethanol and finally dried in hexamethyldisilazane. The analysis was carried out with a SEM JEOL JSM-6490.

\section{MTT assay}

After 21 and 28 days of culture the 3-(4,5-dimethylthiazol-2-yl)-2,5-diphenyl tetrazolium bromide (MTT) assay (Sigma Aldrich) was used to evaluate the metabolic activity of the DPSCs on control and test titanium discs, based on the capability of viable cells to reduce MTT into a colored formazan product. At day 21 and 28 , the medium was replaced medium containing $0.5 \mathrm{mg} / \mathrm{mL} \mathrm{MTT}$ and probed with cells for $5 \mathrm{~h}$ at $37^{\circ} \mathrm{C}$. In order to solubilize salts, the plate was incubated in dimethylsulfoxide (DMSO) solution for $30 \mathrm{~min}$ at $37^{\circ} \mathrm{C}$. Spectrophotometric reading of the optical density was at $570 \mathrm{~nm}$ with a spectrophotometer Anthos 201096 (Anthos Labtec Instruments, Salzburg, Austria). Values obtained in the absence of cells were considered as background.

\section{ELISA test of IL6 and PGE2 secretion}

IL6 and PGE2 secretion in the culture medium was detected by following the instructions provided by the manufacturer protocol. EIA kit (Enzo Life Sciences, Farmingdale, NY, USA) was used to measure IL6 and PGE2 concentrations. The absorption values were obtained by spectrophotometric reading of plates at 450 and $405 \mathrm{~nm}$, respectively, by means of plates for reading in the spectrophotometer 96 Anthos 2010 (Anthos Labtec Instruments). IL6 and PGE2 secretion levels were measured in different wells and normalized for optical density (pg/mL/OD) as previously determined by MTT assay.

\section{RNA extraction}

TRI Reagent (Sigma-Aldrich) was used for total RNA extraction. Briefly, the cells that adhered to titanium discs in each plate well were suspended in $500 \mu \mathrm{L}$ of TRI Reagent. The insoluble material was removed by centrifuging this suspension at 10,000 rpm for $10 \mathrm{~min}$ at $4^{\circ} \mathrm{C}$. After this, the supernatant was removed and added to $100 \mu \mathrm{L}$ of chloroform, vigorously shaken and incubated on ice for $15 \mathrm{~min}$, after which it was centrifuged for $20 \mathrm{~min}$ at $13,200 \mathrm{rpm}$ at $4^{\circ} \mathrm{C}$. The aqueous phase containing RNA was precipitated in 250 $\mu \mathrm{L}$ of isopropanol and stored for $30 \mathrm{~min}$ at $-20^{\circ} \mathrm{C}$. The RNA was pelleted by centrifugation for $20 \mathrm{~min}$ at 13,200 rpm at $4^{\circ} \mathrm{C}$, washed in $500 \mu \mathrm{L}$ of $75 \%$ ethanol, air dried and resuspended in RNase-free water.

The removal of contaminating DNA was performed using DNA-free kit (Life Technologies, Carlsbad, CA, USA). The concentration of RNA was measured by spectrophotometer reading at $260 \mathrm{~nm}$ and its purity was assessed by the ratio at 260 and $280 \mathrm{~nm}$ readings (BioPhotometer Eppendorf, Hamburg, Germany). The quality of extracted RNA was assessed by electrophoresis through agarose gels and visualized by staining with ethidium bromide, under UV light.
Reverse transcription (RT) and real-time RT-polymerase chain reaction (real-time $R T$-PCR)

High Capacity cDNA Reverse Transcription kit (Life Technologies) was used to reverse transcribe $1 \mu \mathrm{g}$ of RNA in a reaction volume of $20 \mu \mathrm{L}$. Reactions were incubated in a 2720 Thermal Cycler (Life Technologies) initially at $25^{\circ} \mathrm{C}$ for $10 \mathrm{~min}$, then at $37^{\circ} \mathrm{C}$ for $2 \mathrm{~h}$ and finally at $85^{\circ} \mathrm{C}$ for $5 \mathrm{~min}$.

Gene expression was determined by quantitative PCR using TaqMan probe-based chemistry. Reactions were performed in 96-well plates on an ABI PRISM 7900 HT Fast Real-Time PCR System (Life Technologies). TaqMan probes and PCR primers were purchased from Life Technologies (TaqMan Gene Expression Assays (20X): Hs00154192_m1 for BMP2 and Hs00231692_m1 for RUNX2, Hs01029144_m1 for ALPL and Hs01866874_s1 for osterix). Glyceraldehyde-3phosphate dehydrogenase (GAPDH) (Life Technologies, Part No. 4333764F) was used as the housekeeping gene. Each amplification reaction was performed with $10 \mu \mathrm{L}$ of TaqMan Fast Universal PCR Master Mix (2X), No AmpErase UNG (Life Technologies), $1 \mu \mathrm{L}$ of primerprobe mixture, $1 \mu \mathrm{L}$ of $\mathrm{cDNA}$ and $8 \mu \mathrm{L}$ of nucleasefree water. No-template control was used to check for contamination. A reverse transcriptase minus control was included for osterix gene assay.

Thermal cycling conditions were: $95^{\circ} \mathrm{C}$ for $20 \mathrm{~s}$, followed by 40 cycles of amplification at $95^{\circ} \mathrm{C}$ for $1 \mathrm{~s}$ and $60^{\circ} \mathrm{C}$ for $20 \mathrm{~s}$. Sequence Detection System software, ver. 2.3 (Life Technologies) elaborated gene expression data. The comparative $2^{-\Delta \Delta \mathrm{Ct}}$ method was used to quantify the relative abundance of mRNA (relative quantification) ${ }^{25}$.

Real-time PCR analysis was performed in four independent experiments. In each experiment, one cDNA sample for each experimental condition was included. Amplification was performed in triplicate for each cDNA sample in relation to each investigated genes.

Gene expression data were collected from each sample used in the experimental procedure and means \pm SEM were obtained for each experimental group. Values were analyzed by one-sample $t$-test. 1 (calibrator sample) was considered the theoretical mean for the comparison.

\section{Alizarin red $S(A R S)$ assay}

ARS is a calcium-sensing dye. Differentiated osteoblasts deposit appreciable extracellular quantities of calcium phosphate (a hallmark of mineralization) which can be detected by ARS. Calcium deposits appear as bright orange-red stained areas.

The wells were washed twice in PBS. PBS was aspirated and the cellular monolayer was fixed with $4 \%$ paraformaldehyde for $15 \mathrm{~min}$ at room temperature and rinsed in deionized water. Forty millimole of ARS staining solution (Sigma-Aldrich) was added and incubated for $20 \mathrm{~min}$ at RT on a shaker. The plates were rinsed five times in deionized water and the orangered stained calcium deposits were made soluble by the following procedure: $10 \%$ acetic acid was added and the plate was shuck for $30 \mathrm{~min}$. Titanium discs were scraped 
and the liquid containing deposits was harvested and vortexed in a tube. Hot mineral oil (Sigma-Aldrich) was added and the tube was kept on ice for $5 \mathrm{~min}$, after which it was centrifuged at $20,000 \times \mathrm{g}$ for $15 \mathrm{~min}$. The supernatant was removed and 10\% ammonium hydroxide was added. This solution was read by a spectrophotometer at $405 \mathrm{~nm}$.

\section{Statistical analysis}

SPSS software (Statistical Package for Social Science) GraphPad Prism 5 was used to perform statistical analysis. $t$-Test was used to evaluate the significance of the difference in results between groups. The results were expressed as means $\pm \mathrm{SD}$. All $p$ values $<0.05$ were considered significant.

\section{RESULTS}

Before starting DPSCs culture on titanium discs, cells were analyzed through flow cytometry to detect molecular markers commonly applied to identify mesenchymal stem cells. SCs consisted of DPSCs showing high expression of cell-surface markers such as CD90, CD105 and to a major extent CD29 and CD73. Moreover, a dim expression of the embryonic stem antigen SSEA-4 is observed. To refine the analysis, the SSEA-4 stained cells were permeabilized to detect also the intracellular levels of the molecule ${ }^{26,27)}$. As expected, the cells are negative for the leukocyte antigen CD45 (Fig. 1).

DPSCs were cultured on control and test titanium discs in a differentiating medium supplemented with

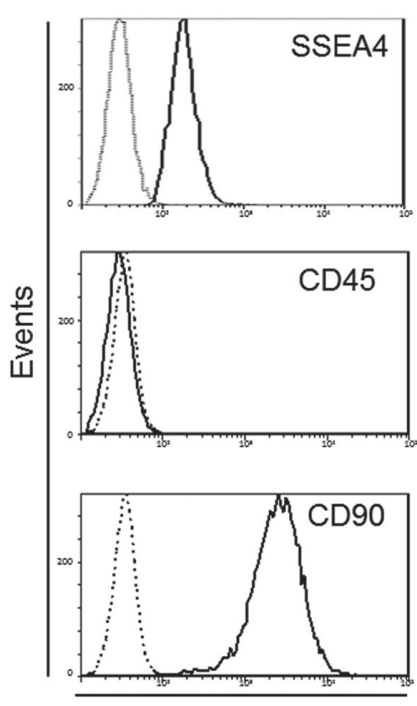

FITC
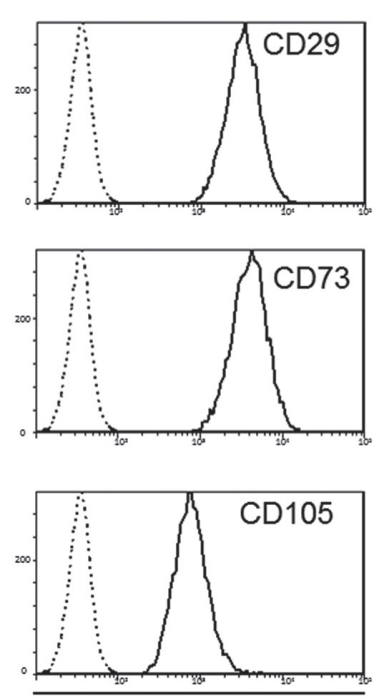

PE
Fig. 1 Antigen expression in DPSCs at the third passage.

Each antigen (continuous line) is plotted with the isotype control at the same experimental time (dashed line). The representative out of three separate experiments is shown. ascorbic acid, dexamethasone and $\beta$-glycerol phosphate for 28 days.

To examine surface topography of control and test titanium discs SEM analysis was performed before seeding cells. Control disc surface shows a great homogeneity while test discs are characterized by peaks and microcavities (Fig. 2).

Then SEM analysis was performed on DPSCs cultured on both control and test titanium discs. After 3 days by the seeding cells are able to attach to both surfaces. On control surfaces cells show fillopodia, thin cytoplasmic projections that extend beyond the leading edge of the cells, indicated by arrows, that contribute to the attachment. On test discs cell surface shows a well evident secretome activity consisting of light granules of extracellular matrix indicated by asterisk (Figs. 3A and B, Figs. 4A and B). This trend is more evident after 7 days of cultures. In both cases cells show a flat and star like feature according to odontoblastic/osteoblastic like cells (Figs. 3C and D, Figs. 4C and D). Starting from 14 days in both surfaces cells spread well and contribute to form an uniform monolayer (Figs. 3E-J and Figs. $4 \mathrm{E}-\mathrm{J})$. MTT analysis was performed after 21 and 28 days of culture, finding that both at day 21 and day 28 of culture no significant differences of cell metabolic activity, which can be considered an indirect evaluation of cellular proliferation rate, between control and test surfaces could be identified (Fig. 5).

To investigate the occurrence of an inflammatory event, ELISA assay was performed to detect IL6 proinflammatory cytokine secretion in the culture medium. IL6 secretion level does not undergo changes between test and control surface after both 21 and 28 days of culture (Fig. 6).

To evaluate the differentiation process of DPSCs towards the osteoblastic lineage both the expression of osteoblastic markers at early and late stages, through
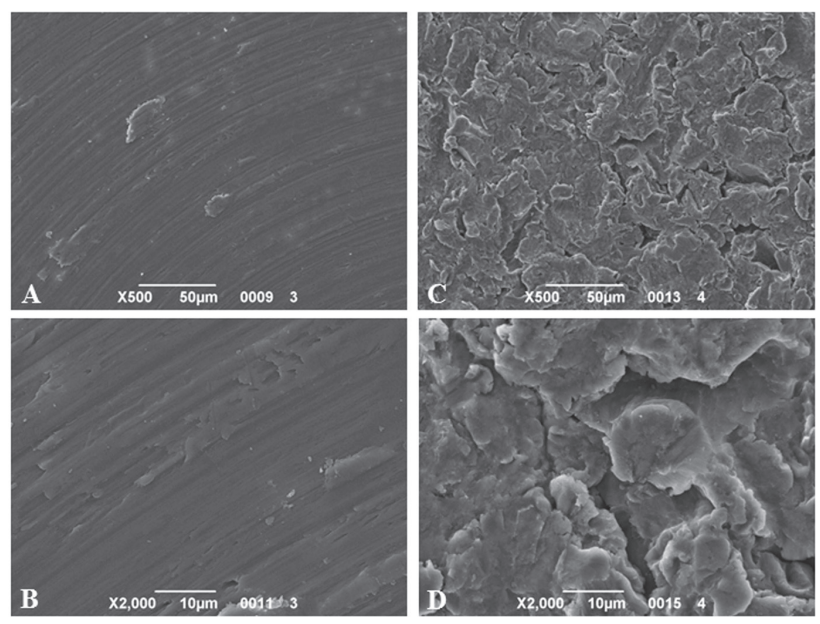

Fig. 2 SEM images of Ctrl discs (A and B) and Test discs (C and D).

Magnification 500× and 2,000×. 
Day 3
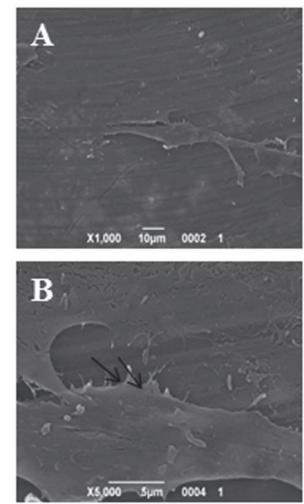

Day 7
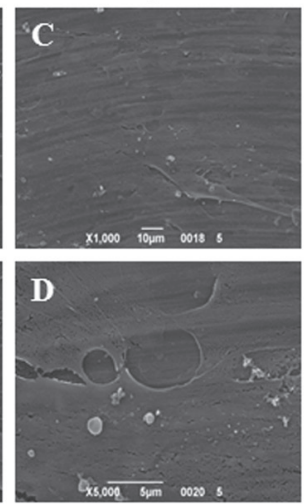

Day 14
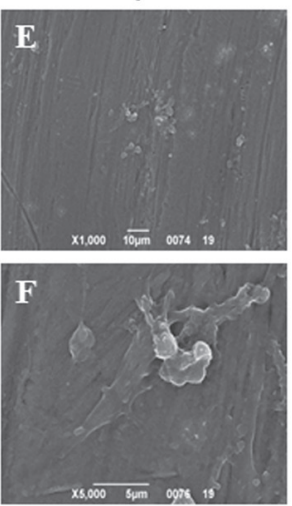

Day 21
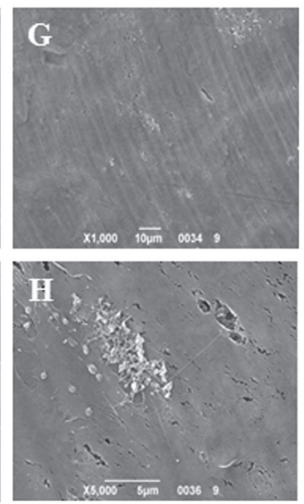

Day 28
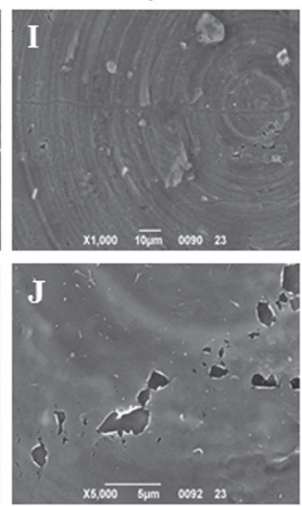

Fig. 3 SEM images of DPSCs cultured on Ctrl discs for 3 (A and B), 7 (C and D), 14 (E and F), 21 (G and H) and 28 days ( $\mathrm{I}$ and $\mathrm{J}$ ).

Arrows indicate fillopodia. Magnification 1,000× and 5,000×.

Day 3
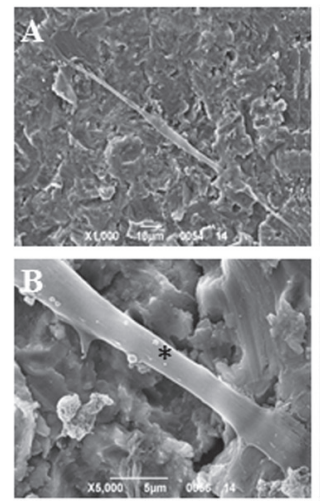

Day 7
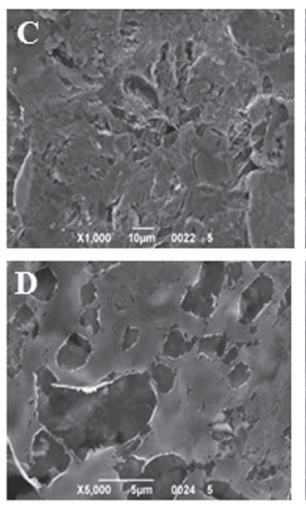

Day 14
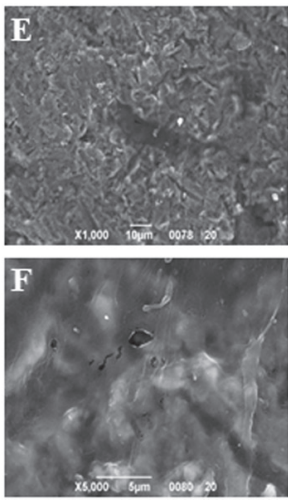

Day 21
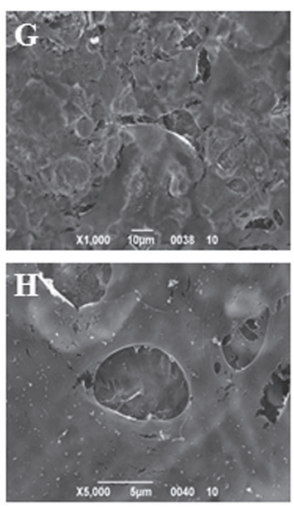

Day 28
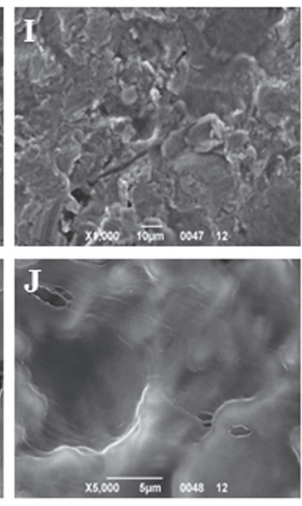

Fig. 4 SEM images of DPSCs cultured on Test discs for 3 (A and B), 7 (C and D), 14 (E and F), 21 (G and H) and 28 days (I and $\mathrm{J}$ ).

Asterisk indicates secretome activity. Magnification 1,000× and 5,000×.

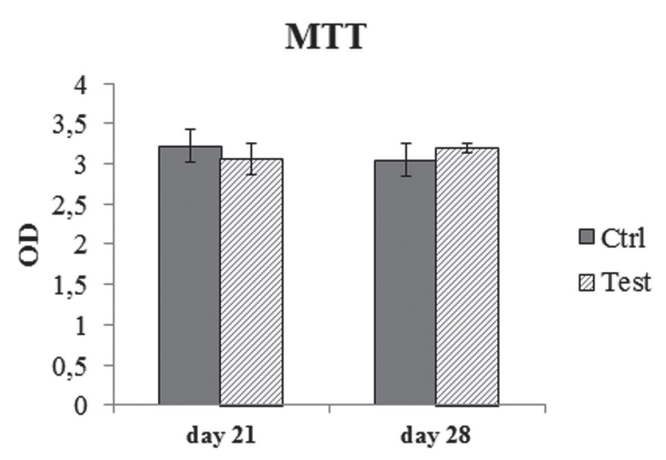

Fig. 5 MTT assay in DPSCs cultured on titanium discs for 21 and 28 days.

The histogram represents optical density (OD) values in control and test discs. Data shown are the mean $( \pm \mathrm{SD})$ of three separate experiments.

\section{IL6}

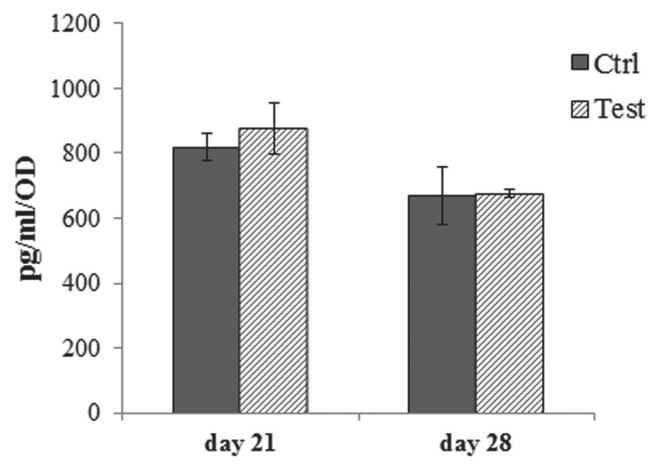

Fig. 6 ELISA assay for IL6 secretion of DPSCs cultured on titanium discs for 21 and 28 days.

Secretion levels are reported as picograms per $\mathrm{mL}$ per MTT optical density (OD) values. The results are the mean $\pm \mathrm{SD}$ of three samples from three different experiments. 
$\mathbf{A}$

BMP2

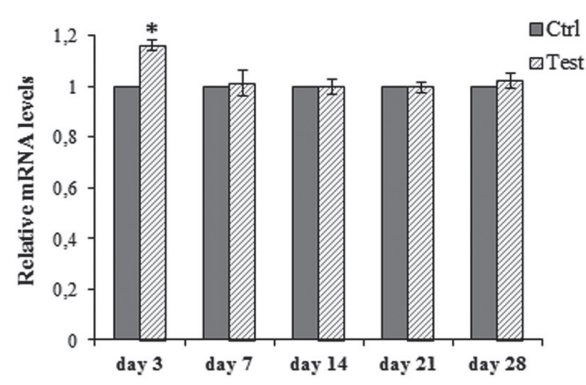

C

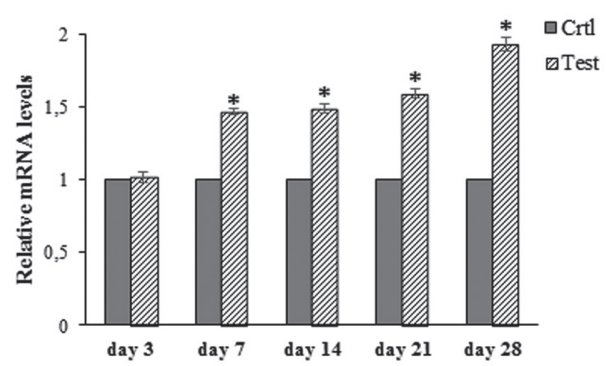

B

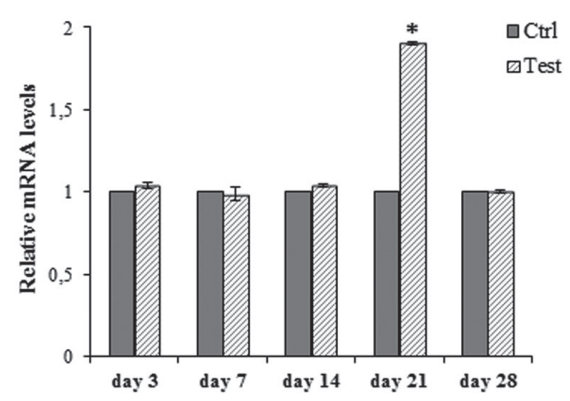

D

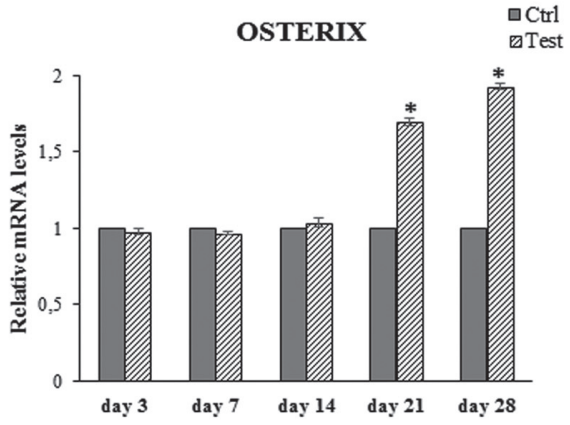

Fig. 7 Relative gene expression of BMP2 (A), RUNX2 (B), ALP (C) and osterix (D) in DPSCs cultured on titanium discs for $3,7,14,21$, and 28 days.

Data are expressed as relative to control (calibrator sample, defined as 1). Values represent the means $\pm \mathrm{SD}$. Y-axis, fold change. The most representative of three separate experiments is shown.

* BMP2 mRNA day 3 Test vs BMP2 mRNA day 3 Ctrl $p<0.01$;

* RUNX2 mRNA day 21 Test vs RUNX2 mRNA day 21 Ctrl $p<0.001$;

*ALP mRNA day 7, day 14, day 21 and day 28 Test vs ALP mRNA day 7, day 14, day 21 and day $28 \mathrm{Ctrl}$, respectively $p<0.001$;

* osterix mRNA day 21, day 28 Test vs osterix mRNA day 21 and day 28 Ctrl, respectively $p<0.001$.

real time RT-PCR, PGE2 secretion level, through ELISA assay, and extracellular matrix deposition at later stages, through Alizarin Red staining, were measured.

BMP2 gene expression is found significantly augmented in the test surface compared to the control one after 3 days of culture, whereas, after 7, 14, 21 and 28 days of culture BMP2 expression levels appear to be similar in test and control surfaces (Fig. 7A). On the other hand, RUNX2 gene expression level does not show any significant difference between test and control surfaces after 3, 7, 14 and 28 days of culture whereas RUNX2 gene expression is increased after 21 days in cells cultured on Test discs respect to control ones (Fig. 7B). Alkaline phosphatase (ALP) gene expression does not show significant differences in cells grown on the two tested surfaces after 3 days while after 7, 14, 21 and 28 days of culture ALP gene expression always appears significantly higher on test surface respect to control (Fig. 7C). Lastly osterix gene expression is significantly higher after both 21 and 28 days of culture in test surfaces respect to control ones (Fig. 7D). PGE2 secretion levels are significantly higher in test compared

\section{PGE2}

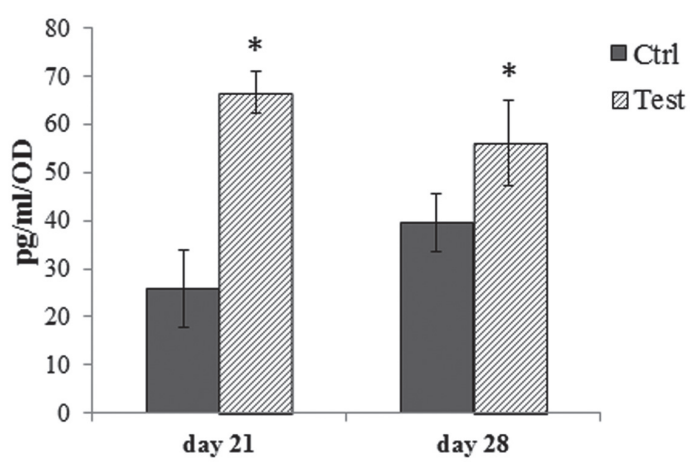

Fig. 8 ELISA assay for PGE 2 secretion of DPSCs cultured on titanium discs for 21 and 28 days.

Secretion levels are reported as picograms per $\mathrm{mL}$ per MTT optical density (OD) values. The results are the mean $\pm \mathrm{SD}$ of three samples from three different experiments.

*day 21 Test $v s$ day $21 \mathrm{Ctrl} p<0.05$

*day 28 Test $v s$ day 28 Ctrl $p<0.05$ 


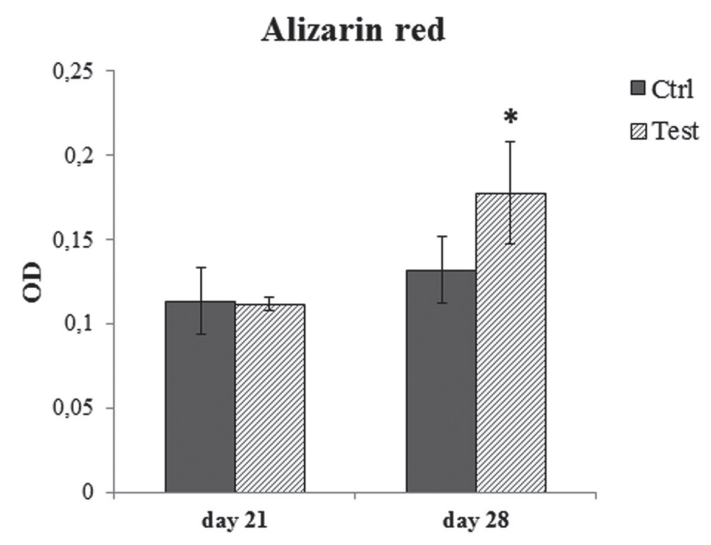

Fig. 9 The histogram represents optical density (OD) values of solubilized orange-red stained calcium deposits.

*day 28 Test $v s$ day $28 \operatorname{Ctrl} p<0.05$

to control samples at both 21 and 28 days of culture (Fig. 8). Alizarin Red staining does not show significant differences in matrix deposition between test and control surfaces after 21 days of culture; however, the difference is significantly increased on test surfaces after 28 days of culture (Fig. 9).

\section{DISCUSSION}

Recently biomedical research was frequently interested in ameliorating bone tissue healing in the bone-toimplant area and in enlarging this little contact region between titanium surfaces and bone tissue.

It was shown that modifying the surface of titanium implants by sandblasting, and therefore increasing the roughness of the surface can have a positive influence on cell growth and differentiation ${ }^{28}$. There is evidence that bone tissue cell adhesion is higher on rougher surfaces than on smooth machined surfaces. However, in order for cells to organize the cytoskeleton and to adhere to an implant surface, intermediate values of roughness are required whereas extremely rough surfaces reduce the overall adhesive strength ${ }^{29}$. For this reason the rough sandblasted surface was treated by organic or inorganic acid etching which smoothened the peaks created by the formation of microcavities, and promoted protein adhesion which is essential for the early stages of bone healing ${ }^{30}$.

It was already reported, in a previous study from our laboratory, performed on the same titanium discs, that the inorganic ions surface coating after acid etching surface was found to be more biocompatible and better tolerated by human osteoblasts ${ }^{9}$. A morphological study of the titanium discs, performed by AFM, reported in our previous work ${ }^{9}$, evidences a nanometric modification of the surface. The innovation of this surface is represented by the surface treatment which create a stable layer on titanium discs able to better promote cell adhesion, as firstly demonstrated by Zizzari et al. ${ }^{9}$, and subsequently by Gehrke et al. ${ }^{24)}$. In the present work, the goal was to better understand if this surface treatment could also have a positive influence on the differentiation of mesenchymal stem cells towards the osteoblastic lineage. DPSCs were identified as a different source of mesenchymal stem cells for odontoblastic/osteoblastic differentiation. DPSCs were chosen for this study because of their easy extraction from the harvested dental pulp and their high odontogenic/osteogenic ability $^{311}$. In standard culture conditions more than $60 \%$ of the cell population used in this study was positive for mesenchymal antigens CD90, CD105, CD29, CD73, while they are negative for the leukocyte antigen CD45. They also showed a strong adhesion to plastic surfaces and the potential to differentiate in several cell types. These features were in accordance with the criteria of the Mesenchymal and Tissue Stem Cell Committee of the ISCT, proving that the cells used were mesenchymal stem cells $\mathrm{s}^{32}$. To stimulate and accelerate the differentiation towards the osteoblastic lineage a differentiation medium was applied in DPSCs culture. Osteoblasts proliferation around the implant is the basis of the osteointegration process. Cell metabolic activity and morphological features were investigated after seeding on both surfaces. Both implants preserved cell viability, thus suggesting that the new tested surface allowed good cell proliferation, as did the control one even if the secretion of organic and inorganic molecules of the cells grown on test surface immediately appears pronounced thus letting us hypothesize that the new surface better and faster promotes osteoblastic differentiation. Furthermore, the results obtained for interleukin-6 (IL-6) indicated that the test surface did not provoke a higher inflammation response than the control surface. IL-6 produced by osteoblasts and their precursors lead to bone resorption by stimulating the differentiation and activation of osteoclasts ${ }^{33,34)}$. The relatively low levels of IL- 6 release on both surfaces suggested that it could not be sufficient to recruit osteoclast precursors and support osteoclastic activity.

BMP2 was recognized to stimulate bone formation around endosseous implants and is considered to be the most osteogenic bone morphogenetic protein ${ }^{35}$. The significantly higher BMP2 gene expression on test surfaces at very early stages (3 days) implied that the test surface had a stronger and more prompt effect on inducing DPSCs differentiation into osteoblasts than the control surface.

Regarding the comparison of the two surfaces effects, quantitative RT-PCR showed significant difference between the expression of RUNX2 only after 21 days of culture RUNX2 is an important transcriptional modulator of osteoblast differentiation, maturation and homeostasis, it showed that its role is in the earlier stages of multipotent stem cell activation and differentiation towards the osteoblast lineage ${ }^{36)}$ even if several studies underline that an appreciable increase of RUNX2 gene expression is generally recognizable after two weeks of culture ${ }^{37,38)}$. In our experimental model an increase of RUNX2 gene expression, detectable 
after 3 weeks of culture, is paralleled by an increase of osterix gene expression which is maintained until the fourth week of culture. RUNX2 in fact seems to act upstream of osterix as shown by several studies which have demonstrated that in RUNX2 null mice, osterix is not expressed whereas in osterix null mice RUNX2 is expressed ${ }^{39}$. Finally DPSCs cultured on new Test surface, starting from the first week of culture, clearly reveal high levels of ALP gene expression, which is known to be a clear evidence of differentiation towards the osteoblastic phenotype. ALP is in fact commonly considered an osteoblast marker as it is associated with calcification events ${ }^{40)}$.

Even though high levels of prostaglandins are associated with inflammation, prostaglandins are important mediators of osteoblastic differentiation. PGE2 is needed for the increase of TGF- $\beta 1$ and both molecules are needed in later stages for DPSCs terminal differentiation by increasing alkaline phosphatase specific activity ${ }^{41-433}$. In the present model an increase of PGE2 secretion level released by cells grown on test compared to those exposed to control surfaces was recorded, thus confirming the hypothesis of a more prominent osteoblastic differentiation on test surfaces. This finding was further supported by extracellular matrix deposition which was significantly augmented on test surfaces.

According to this evidence different performances of test respect to untreated surface are probably due to more than one factor. Firstly, surface treatment with inorganic ions induces a significant roughness modification which is responsible, in turn, of an increased cell adhesion and of a reduced osteoblasts cytotoxicity, as demonstrated in our previous paper ${ }^{9}$. Furthermore, it can be argued that magnesium and calcium addition on test surface plays a pivotal role in promoting and enhancing cell differentiation thus improving bone-implant contact, as supported by the scientific literature ${ }^{21,22,24)}$. However the reasons of this outcome still remain unknown and need to be clarified in future studies. Finally it can be also hypothesized that surface wettability increase, due to both maleic acid and inorganic ions treatment, is able to bind extracellular matrix produced by osteoblasts, thus triggering a positive feedback which leads to further matrix deposition.

\section{CONCLUSIONS}

The present results indicated that the new sandblasted and acid etched surfaces, followed by inorganic ion treatment, could guarantee a good cell viability along with a low inflammatory response and, at the same time they promote the osteoblastic differentiation. All in all the obtained data can represent a good start point for in vivo studies which aim to investigate the molecular mechanisms underlying bone tissue cells osteoinductive response to titanium implants.

\section{ACKNOWLEDGMENTS}

Authors would like to thank MIUR FIRB-Accordi di Programma 2010 Project 'Processi degenerativi dei tessuti mineralizzati del cavo orale, impiego di biomateriali e controllo delle interazioni con i microrganismi dell'ambiente', CARICHIETI and PO FSE Abruzzo 2007-2013 -Progetto "Innovazione, Sviluppo e Competitività" for the fellowship attributed to Dr. V.L. Vizzari and M. De Colli, respectively. No benefit of any kind was given either directly or indirectly to all the authors. Authors would like to thank Dr. Alessandro Marrone for his helpful chemical explanations.

\section{CONFLICTS OF INTEREST}

The authors declare that they have no conflicts of interest.

\section{REFERENCES}

1) Lambrecht J, Thomas Künzel AR, Schiel HJ. Long-term evaluation of submerged and nonsubmerged ITI solidscrew titanium implants: a 10-year life table analysis of 468 implants. Int J Oral Maxillofac Implants 2003; 18: 826-834.

2) Lindquist LW, Carlsson GE, Jemt T. A prospectpressive 15-year follow-up study of mandibular fixed prostheses supported by osseointegrated implants. Clinical results and marginal bone loss. Clin Oral Implants Res 1996; 7: 329-336.

3) Albrektsson T, Zarb G, Worthington P, Eriksson AR. The longterm efficacy of currently used dental implants: a review and proposed criteria of success. Int J Oral Maxillofac Implants 1986; 1: 11-25.

4) Triplett RG, Frohberg U, Sykaras N, Woody RD. Implant materials, design and surface topographies: their influence on osseointegration of dental implants. J LongTerm Eff Med Implants 2003; 13: 485-502.

5) Davies JE. Mechanisms of endosseous integration. Int J Prosthodont 1998; 11: 391-401.

6) Shalabi MM, Wolke JG, Jansen JA. The effects of implant surface roughness and surgical technique on implant fixation in an in vitro model. Clin Oral Implants Res 2006; 17: 172178.

7) Schwarz, F, Wieland M, Schwartz Z, Zhao G, Rupp F, GeisGerstorfer J, Schedle A, Broggini N, Bornstein MM, Buser D, Ferguson SJ, Becker J, Boyan BD, Cochran DL. Potential of chemically modified hydrophilic surface characteristics to support tissue integration of titanium dental implants. J Biomed Mater Res B Appl Biomater 2009; 88: 544-557.

8) Qu Z, Rausch-Fan X, Wieland M, Matejka M, Schedle A. The initial attachment and subsequent behavior regulation of osteoblasts by dental implant surface modification. J Biomed Mater Res A 2007; 82: 658-668.

9) Zizzari VL, Marconi GD, De Colli M, Zara S, Zavan B, Salini V, Fontana A, Cataldi A, Piattelli A. In vitro behavior of primary human osteoblasts onto microrough titanium surface. Implant Dent 2015; 24: 377-383.

10) Buser D, Broggini N, Wieland M, Schenk RK, Denzer AJ, Cochran DL, Hoffmann B, Lussi A, Steinemann SG. Enhanced bone apposition to a chemically modified SLA titanium surface. J Dent Res 2004; 83: 529-533.

11) Eriksson C, Nygren H, Ohlson K. Implantation of hydrophilic and hydrophobic titanium discs in rat tibia: cellular reactions on the surfaces during the first 3 weeks in bone. Biomaterials 2004; 25: 4759-4766. 
12) Gronthos S, Brahim J, Li W, Fisher LW, Cherman N, Boyde A, DenBesten P, Robey PG, Shi S. Stem cells properties of human dental pulp stem cells. J Dent Res 2002; 81: 531-535.

13) D’Aquino R, Graziano A, Sampaolesi M, Laino G, Pirozzi G, De Rosa A, Papaccio G. Human postnatal dental pulp cells codifferentiate into osteoblasts and endotheliocytes: a pivotal synergy leading to adult bone tissue formation. Cell Death Differ 2007; 14: 1162-1171.

14) De Coppi P, Bartsch G Jr, Siddiqui MM, Xu T, Santos CC, Perin L, Mostoslavsky G, Serre AC, Snyder EY, Yoo JJ, Furth ME, Soker S, Atala A. Isolation of amniotic stem cell lines with potential for therapy. Nat Biotechnol 2007; 25: 100-106.

15) Ivanovski S, Gronthos S, Shi S, Bartold PM. Stem cells in the periodontal ligament. Oral Dis 2006; 12: 358-363.

16) Ballini A, De Frenza G, Cantore S, Papa F, Grano M, Mastrangelo F, Tetè $\mathrm{S}$, Grassi FR. In vitro stem cell cultures from human dental pulp and periodontal ligament: new prospects in dentistry. Int J Immunopathol Pharmacol 2007; 20: 9-16.

17) Gronthos S, Mankani M, Brahim J, Robey PG, Shi S. Postnatal human dental pulp stem cells (DPSCs) in vitro and in vivo. Proc Natl Acad Sci USA 2000; 97: 13625-13630.

18) Otaki S, Ueshima S, Shiraishi K, Sugiyama K, Hamada S, Yorimoto M, Matsuo O. Mesenchymal progenitor cells in adult human dental pulp and their ability to form bone when transplanted into immunocompromised mice. Cell Biol Int 2007; 31: 1191-1197.

19) Graziano A, d'Aquino R, Laino G, Papaccio G. Dental pulp stem cells: a promising tool for bone regeneration. Stem Cell Rev 2008; 4: 21-26.

20) Goto N, Fujimoto K, Fujii S, Ida-Yonemochi H, Ohshima H, Kawamoto T, Noshiro M, Shukunami C, Kozai K, Kato Y. Role of MSX1 in osteogenic differentiation of human dental pulp stem cells. Stem Cells Int 2016; 2016: 8035759.

21) Cai YL, Zhang JJ, Zhang S, Venkatraman SS, Zeng XT, Du HJ, Mondal D. Osteoblastic cell response on fluoridated hydroxyapatite coatings: the effect of magnesium incorporation. Biomed Mater 2010; 5: 054114.

22) Landi E, Tampieri A, Mattioli-Belmonte M, Celotti G, Sandri M, Gigante A, Fava P, Biagini G. Biomimetic mg-and mg, co3substituted hydroxyapatites: Synthesis characterization and in vitro behaviour. J Eur Ceram Soc 2006; 26: 2593-2601.

23) Ota-Tsuzuki C, Datte CE, Nomura KA, Gouvea Cardoso LA, Shibli JA. Influence of titanium surface treatments on formation of the blood clot extension. J Oral Implantol 2011; 37: 641-647.

24) Gehrke SA, Maté Sánchez de Val JE, Fernández Domínguez M, de Aza Moya PN, Gómez Moreno G, Calvo Guirado JL. Effects on the osseointegration of titanium implants incorporating calcium-magnesium: a resonance frequency and histomorphometric analysis in rabbit tibia. Clin Oral Implants Res 2016 (in press).

25) Livak KJ, Schmittgen TD. Analysis of relative gene expression data using real-time quantitative PCR and the 2(-Delta Delta C(T)) Method. Methods 2001; 25: 402-408.

26) Pipino C, Pierdomenico L, Di Tomo P, Di Giuseppe F, Cianci E, D'Alimonte I, Morabito C, Centurione L, Antonucci I, Mariggiò MA, Di Pietro R, Ciccarelli R, Marchisio M, Romano M, Angelucci S, Pandolfi A. Molecular and phenotypic characterization of human amniotic fluid-derived cells: A morphological and proteomic approach. Stem Cells Dev 2015; 24: $1415-1428$

27) Trilck M, Hübner R, Seibler P, Klein C, Rolfs A, Frech MJ. Niemann-Pick type $\mathrm{C} 1$ patient-specific induced pluripotent stem cells display disease specific hallmarks. Orphanet J
Rare Dis 2013; 18: 144.

28) Boyan BD, Lossdörfer S, Wang L, Zhao G, Lohmann CH, Cochran DL, Schwartz Z. Osteoblasts generate an osteogenic microenvironment when grown on surfaces with rough microtopographies. Eur Cells Mater 2003; 6: 22-27.

29) Bagno A, Di Bello C. Surface treatments and roughness properties of Ti based biomaterials. J Mater Sci Mater Med 2004; 15: 935-949.

30) Wennerberg A, Albrektsson T. Effects of titanium surface topography on bone integration: A systematic review. Clin Oral Implants Res 2009; 20: 172-184.

31) Karbanová J, Soukup T, Suchánek J, Mokrý J. Osteogenic differentiation of human dental pulp-derived stem cells under various ex-vivo culture conditions. Acta Medica 2010; 53: 7984.

32) Dominici M, Le Blanc K, Mueller I, Slaper-Cortenbach I, Marini F, Krause D, Deans R, Keating A, Prockop Dj, Horwitz E. Minimal criteria for defining multipotent mesenchymal stromal cells. The International Society for Cellular Therapy position statement. Cytotherapy 2006; 8: 315-317.

33) Ishimi $\mathrm{Y}$, Miyaura $\mathrm{C}$, Jin $\mathrm{CH}$, Akatsu T, Abe E, Nakamura Y, Yamaguchi A, Yoshiki S, Matsuda T, Hirano T. IL-6 is produced by osteoblasts and induces bone resorption. J Immunol 1990; 145: 3297-3303.

34) Kwan Tat S, Padrines M, Théoleyre S, Heymann D, Fortun Y. IL-6, RANKL,TNF-alpha/IL-1: interrelations in bone resorption pathophysiology. Cytokine Growth Factor Rev 2004; 15: 49-60.

35) Cochran DL, Schenk R, Buser D, Wozney JM, Jones AA. Recombinant human bone morphogenetic protein-2 stimulation of bone formation around endosseous dental implants. J Periodontol 1999; 70: 139-150.

36) Vimalraj S, Arumugam B, Miranda PJ, Selvamurugan N Runx2: Structure, function, and phosphorylation in osteoblast differentiation. Int J Biol Macromol 2015; 78: 202-208.

37) Farshdousti Hagh M, Noruzinia M, Mortazavi Y, Soleimani M, Kaviani S, Abroun S, Dehghani Fard A, Mahmoodinia M. Different methylation patterns of RUNX2, OSX, DLX5 and BSP in osteoblastic differentiation of mesenchymal stem cells. Cell J 2015; 17: 71-82.

38) Natu VP, Dubey N, Loke GC, Tan TS, Wee Hsuan NG, Yong CW, Cao T, Rosa V. Bioactivity, physical and chemical properties of MTA mixed with propylene glycol. J Appl Oral Sci 2015; 23: 405-411.

39) Nakashima K, Zhou X, Kunkel G, Zhang Z, Deng JM, Behringer RR, de Crombrugghe $\mathrm{B}$. The novel zinc fingercontaining tran-scription factor osterix is required for osteoblast differentiation and bone formation. Cell 2002; 108: 17-29.

40) Ram VS, Parthiban Sudhakar U, Mithradas N, Prabhakar R. Bonebiomarkers in periodontal disease: a review article. $J$ Clin Diagn Res 2015; 9: ZE07-10.

41) Dziak RM, Hurd D, Miyasaki KT, Brown M, Weinfeld N, Hausmann E. Prostaglandin E2 binding and cyclic AMP production in isolated bone cells. Calcif Tissue Int 1983; 35: 243-249.

42) Sabbieti MG, Marchetti L, Abreu C, Montero A, Hand AR, Raisz LG, Hurley MM. Prostaglandins regulate the expression of fibroblast growth factor-2 in bone. Endocrinology 1999; 140: 434-444.

43) Sisk MA, Lohmann CH, Cochran DL, Sylvia VL, Simpson JP, Dean DD, Boyan BD, Schwartz Z. Inhibition of cyclooxygenase by indomethacin modulates osteoblast response to titanium surface roughness in a time-dependent manner. Clin Oral Implants Res 2001; 12: 52-61. 